\title{
THE MORRISON FORMATION Extinct ECOSystems ProjeCt
}

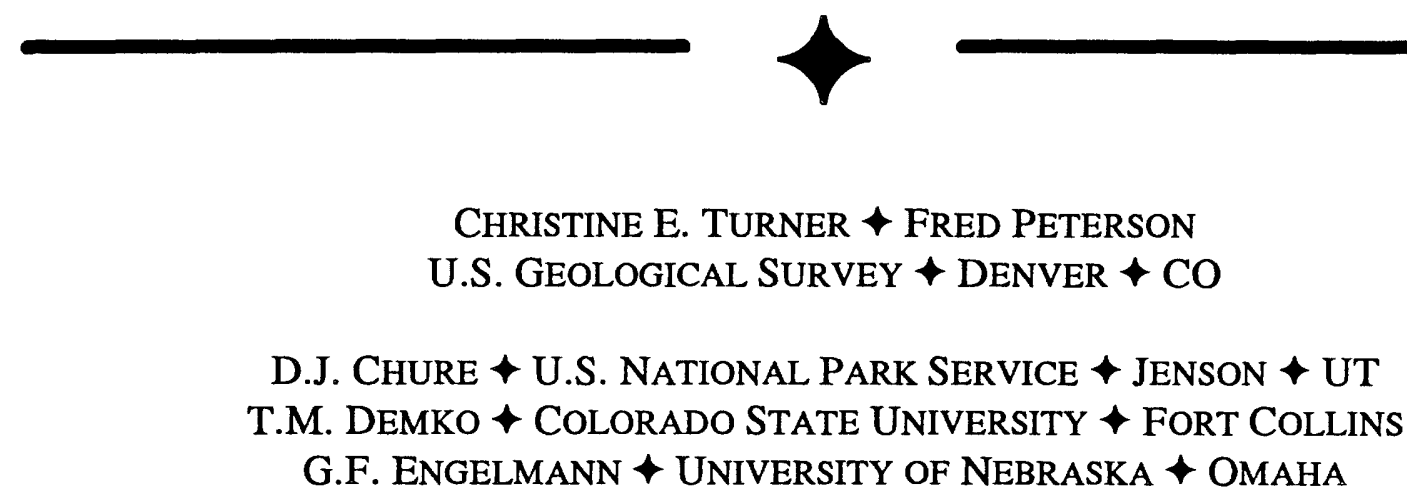

\section{$\downarrow \quad$ ABSTRACT}

The Morrison Extinct Ecosystem project is generating interesting results that, although preliminary in nature, are starting to converge on an integrated reconstruction of the Late Jurassic habitat in the Western Interior of the United States. A workshop in April, 1996, helped the participants learn where their data are in agreement and where remaining inconsistencies in the data exist. The workshop thus helped focus collective and individual efforts for the remaining field season so that additional field research and sample collection could be directed toward addressing the unresolved questions. A much more complete picture of the Morrison ecosystem is emerging, with such lines of evidence as the isotopic data confirming regional tectonic interpretations, and trace fossils adding subtle but significant clues to the interpretations of the ancient climate and water-table position and fluctuations.

A mesic climate interpretation with a moderate amount of available moisture is derived from some of the plant fossils and, at first glance, contrasts with evidence of an arid to semi-arid climate based on the presence of saline, alkaline lake deposits; eolian strata; and evaporite deposits. Thus, the climate may have changed periodically or episodically, leaving evidence in the geologic record of the contrasting climate regimes-not all of which existed at the same time. A possible resolution of these discrepancies is that there was marked seasonality in which part of the year was relatively dry, as reflected by the arid to semiarid environmental indicators, whereas there may have been more precipitation during other parts of the year, as reflected by the more mesic environmental indicators. An additional factor that will need to be evaluated further is the role of the water table. The trace fossils suggest a fairly shallow water table that many of the plants, especially the larger ones, could tap throughout the year and therefore not be unduly affected by seasonal dryness. Also to be evaluated is the possibility that plants grew near stream courses or in overbank ponds in areas having a high water table, and that areas away from the streams were drier. These issues will be the focus of the remaining work, as outlined at the conclusion of the workshop.

\section{INTRODUCTION}

The Morrison Formation Extinct Ecosystems Project, hereafter called the Morrison Project, began on June 1 of 1994 . The project is a multidisciplinary endeavor designed to determine the nature, distribution, and evolution of the ancient ecosystems that existed in the Western Interior of the United States during the Late Jurassic Epoch 
when the Morrison Formation and related coeval rocks, such as the Junction Creek Sandstone and the Ralston Creek Formation, were deposited. The information obtained from the research can be used to suggest appropriate resource management actions. The project will also provide an improved understanding of the geological and paleontological history of these National Park Service units and better information for interpretive programs and publications.

The Morrison Extinct Ecosystem Project is at the end of its second year, with one year remaining to completion. At this juncture, it was thought advisable to hold a workshop among the project participants in order to evaluate the progress thus far and to focus the remaining field and laboratory studies to ensure that the project goals are attained. The workshop was held April 12-14, 1996 at the U.S. Geological Survey in Denver, Colorado. Participants were asked to prepare presentations of their data so that we could collectively evaluate where the group was reaching agreement (convergence) and where remaining controversies (points of divergence) remained. This Annual Report is largely a summary of the workshop, with the current but preliminary status of knowledge and interpretations that have been generated thus far by the project participants.

The Morrison Formation in the National Park Service's Rocky Mountain Region (largely in the Western Interior physiographic province of the United States) is one of science's best windows onto the world of dinosaurs and Mesozoic ecosystems. Because of its varied environments, rich fossil deposits, extensive rock exposures, and broad geographic distribution, the formation offers an outstanding opportunity for a multi-park, interdisciplinary approach to the evolution of environments, habitats, communities, and climate through some 8 million years (my) of Earth history. The formation covers some 700,000 square miles in the Western Interior (Fig 1) and is world renowned for its rich concentration of dinosaur remains with more than 100 quarries identified to date and new localities continue to be discovered yearly. The formation also contains locally abundant and diverse fossil plant and other animal communities that were contemporaries of the dinosaurs and that shed light onto the nature of the Late Jurassic ecosystem.

The Morrison Formation and related beds were deposited in a variety of environments in an extensive depositional basin in the Western Interior of the United States and southwestern Canada (Fig. 1). It was deposited primarily by streams that carried their detritus eastward from the Elko Highlands farther west, and northeastward from the Mogollon Slope farther southwest (Figs. 2, 3). The precise structural nature of these highland source regions is unclear but is being studied closely by many geologists in the general scientific community. Marine strata are scarce in the Morrison, being confined to the base of the formation throughout most of the region. However, in northernmost Montana and southwestern Canada, marine rocks are present higher in the Morrison and related beds. How the marine beds are related to Late Jurassic oceans is unclear, but the marine strata probably were deposited in a marine embayment that connected with the paleo-oceans to the north through Alberta and perhaps Saskatchewan. Because the Morrison is truncated by Cretaceous strata around the periphery of the basin outlined in Figure 1, the original extent of the formation is unknown. It is clear from paleocurrent studies in fluvial sandstone beds, however, that Morrison streams in the southernmost part of the region flowed toward the southeast and therefore eventually must have entered the Late Jurassic Gulf of Mexico in central or southern Texas. Another marine embayment in the Chihuahua Trough (Figs. 2, 3) was present in westernmost Texas and adjacent Mexico. It extended into southernmost New Mexico, but was entirely separated from the Morrison depositional basin by poorly defined lowlands slightly farther north in southern New Mexico.

Throughout most of the region, the proper stratigraphic name is Morrison Formation, but there are several areas where other formation names have been applied to strata that correlate with some part of the Morrison. We apply the name Morrison Formation to all strata between the J-5 unconformity at the base to the K-1 unconformity at the top as the Morrison is usually recognized throughout a large part of the Colorado Plateau. 


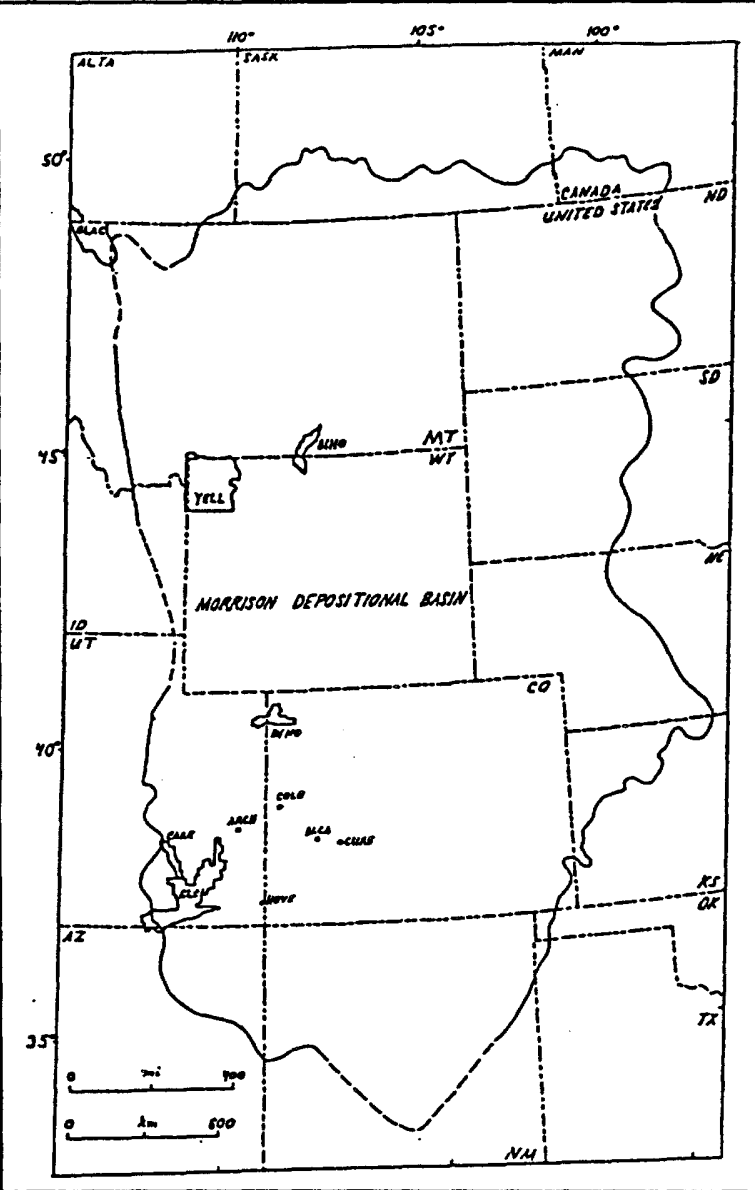

Figure 1.-The Morrison depositional basin in the Western Interior of the United States and southern Canada. Also shown are National Park Service units that contain significant exposures of the Morrison Formation.

In sosuthwestern Colorado, the Junction Creek Sandstone lies above the J-5 unconformity and is a local formation name given to eolian sandstone deposits that correlate with and are physically connected to the Bluff Sandstone Member of the Morrison that is recognized in adjacent parts of southerastern Utah, northwestern Arizona, and northwestern New Mexico. Because the Bluff and Junction Creek together constitute a single large redominantly eolian sandstone unit, they are together referred to as the Bluff-Junction Creek deposits in this teport.

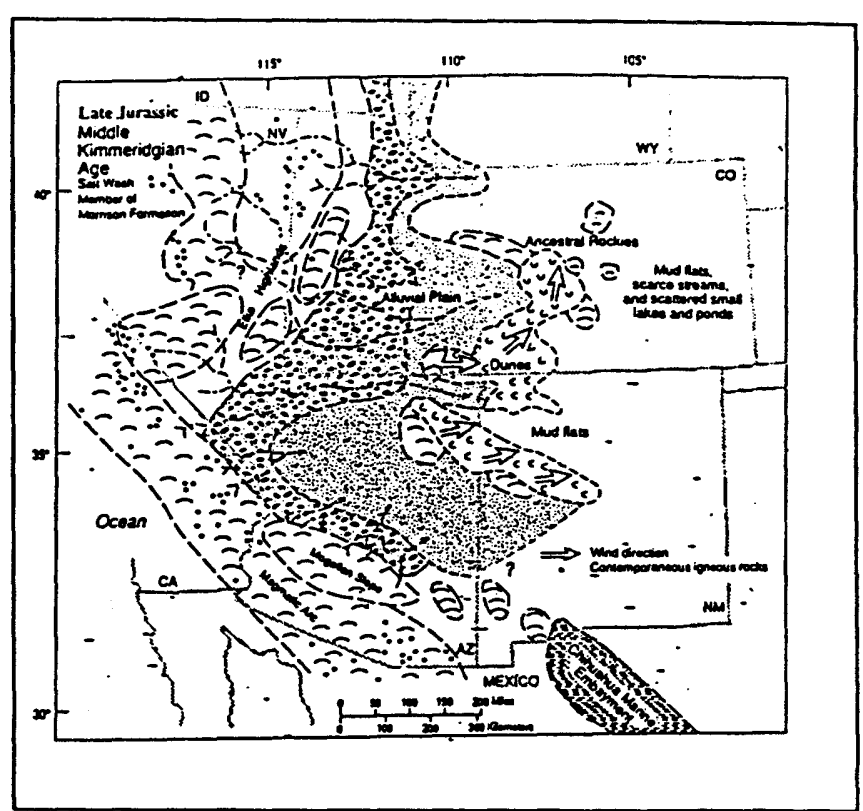

Figure 2.-Paleogeography of the southern part of the Western Interior Basin during about middle Kimmeridgian time and deposition of the Salt Wash Member of the Morrison Formation and related beds. Slightly elevated regions within the depositional basin are indicated by broad concave-downward arcs, eolian dunefields are indicated by small concave eastward or northeastward arcs.

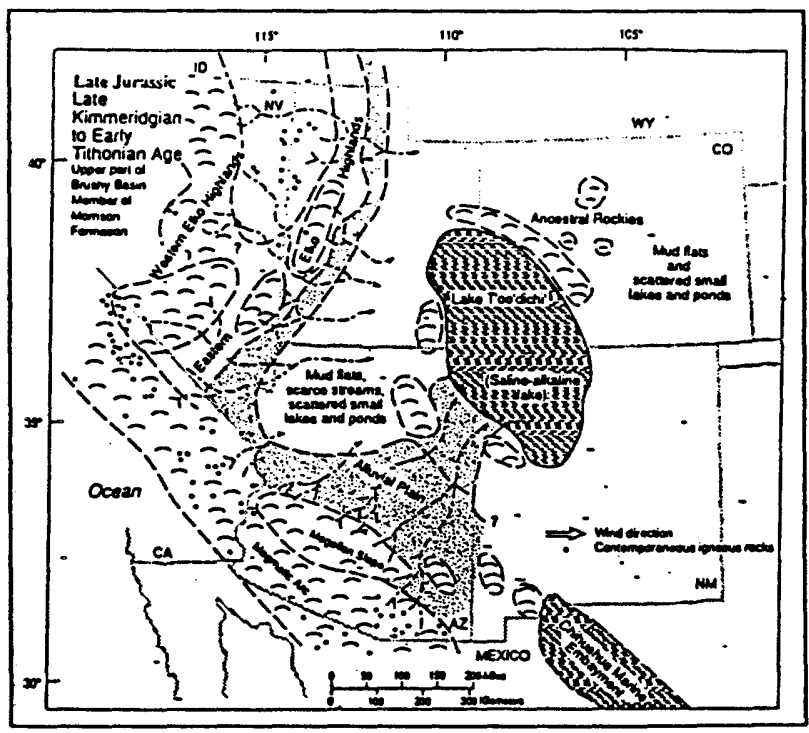

Figure 3.-Paleogeography of the southem part of the Western Interior Basin during about late Kimmeridgian or early Tithonian time and deposition of the upper part of the Brushy Basin Member of the Morrison Formation and related beds. Slightly elevated regions within the depositional basin are indicated by broad concave-downward arcs. 
In a short $25 \mathrm{~km}(15 \mathrm{mi})$ north-south stretch of exposures just west of Denver, Colorado, the Ralston Creek Formation is recognized beneath the Morrison Formation. The Ralston Creek lies on the J-5 unconformity, interfingers at the top with basal beds of the Morrison, and consists largely of strata that cannot be distinguished from the Morrison where a prominent sandstone bed is missing at the base of the overlying Morrison. Because a prominent sandstone bed is not present at the base of the Morrison in many areas north and south from this rather limited part of the outcrop belt, we only recognize Ralston Creek in that limited stretch of exposures just west of Denver.

In some localities in the easternmost part of the Colorado Plateau, some of the lowermost beds of what has been mapped as the Burro Canyon Formation lie below the K-1 unconformity and are logically part of the Morrison depositional sequence. We include these beds in the Morrison Formation and restrict the Burro Canyon Formation to strata above the K-1 unconformity.

Throughout a large part of central Wyoming, many geologists place the upper Morrison contact at a prominent change in clay minerals, from non-smectitic (non-swelling) clays below to predominantly smectitic (swelling) clays above, and include the beds above the clay change in the Lower Cretaceous Cloverly Formation. By bringing the correlations north and northeastward from the Colorado Plateau and southeastward from west-central Montana, we are able to demonstrate that the clay change is within the Morrison Formation and that the proper contact with the Cloverly Formation is significantly higher (by about $30 \mathrm{~m}$ or $100 \mathrm{ft}$ ) and well within the zone of strata dominated by smectitic clay minerals. We therefore restrict the Cloverly to strata above the K-1 unconformity based upon criteria that were discussed in an earlier semiannual report (Turner and Peterson, 1996).

As shown in Figure 1, strata that correlate with the Morrison Formation extend into southern Canada where these rocks are known by entirely different names. From west to east in the northernmost part of Figure 1, these are the upper part of the Fernie Formation, the Morrissey Sandstone, and lower part of the Mist Mountain Formation in southeastern British Columbia and southwestern Alberta; the Swift Formation farther east in southern Alberta; and the Masefield
Formation and lower part of the Success Formation in southern Saskatchewan. In southwestern Manitoba, the uppermost beds of the Waskada Formation may correlate with lowermost Morrison strata or, as seems more likely, the entire Waskada may be slightly older and correlate with the Redwater Shale Member of the Sundance Formation in the United States.

Although a study of the Canadian rocks is beyond the scope of this investigation, they are important because they are largely marine in origin and thereby provide additional information on the paleogeographic setting of the Morrison Formation in the northernmost part of the Western Interior. In northern Montana, this helps to explain an anomalous occurrence of marine sandstone beds in about the middle of the Morrison and well above the known marine strata at the base of the formation. Also in Montana, the Canadian marine strata at higher stratigraphic levels suggest that the coal beds in the uppermost part of the Morrison probably were deposited behind a marine shoreline rather than within an entirely inland coal basin.

\section{STUDY AREA}

The Morrison depositional basin covers much of the Western Interior of the United States. Its present-day extent ranges from northern Arizona and northern New Mexico northward to northern Montana and into southern Canada (Fig. 1). The Morrison Formation has significant exposures in many units within the Rocky Mountain Region of the National Park Service. These include Arches National Park, Bighorn National Recreation Area, Black Canyon of the Gunnison National Monument, Capitol Reef National Park, Colorado National Monument, Curecanti National Recreation Area, Dinosaur National Monument, Glacier National Park, Glen Canyon National Recreation Area, Hovenweep National Monument, and Yellowstone National Park. In addition, the formation is not exposed at the surface but is present beneath approximately 10 other National Park Service units in the Western Interior.

\section{METHODS}

The methods employed by the different investigators vary considerably because of the wide variety of specialties involved. However, the overall 
approach has remained constant in that the investigators are pursuing their own research studies with the goal of integrating those pursuits with the research of the other investigators to determine various aspects of the Morrison ecosystem.

\section{CONCLUSIONS}

The Morrison Project is a multidisciplinary effort designed to investigate the nature and evolution of environments, habitats, communities, and climate in and near many National Park Service units in the Western Interior of the United States through some 8 million years of Earth history when the Upper Jurassic Morrison Formation was deposited. The first two years of the project were devoted primarily to gathering information that would form the basis for later interpretations.

Hence, scientific interpretations concerning the ancient Morrison ecosystem are tentative in this report because of the regency of the research. The Morrison Formation was studied mostly in Utah, Colorado, Wyoming, and Montana but also to some extent in Arizona and New Mexico to provide a more accurate regional framework and to collect samples that might require long preparation time in the laboratory. Included here are brief discussions of interpretations according to major subspecialty categories.

\section{STRATIGRAPHY AND SEDIMENTOLOGY}

Regional stratigraphic and sedimentologic studies demonstrate that strata deposited in relatively dry environments are fairly common in the Morrison Formation in the southern and central parts of the Western Interior. These include extensive evaporite deposits (chiefly gypsum) in the lowermost part of the formation in Utah and Colorado and locally in eastern Wyoming; large eolian dune field deposits (erg deposits) at or near the Four Corners area; small eolian sandstone beds scattered through Arizona, Utah, Colorado, and extending as far north as northern Wyoming; and the rather extensive alkaline, saline lake deposits of ancient Lake T'oo'dichi' in the eastern part of the Colorado Plateau. Farther north in west-central Montana, extensive coal beds in the upper part of the Morrison suggest deposition there was in a more humid climate than existed farther south.
Fluvial and overbank architectural styles are suggestive of seasonally wet-dry precipitationdischarge regimes. Floodplain paleosols in the Morrison Formation are associated with each of the fluvial deposits. Thin floodplain paleosols in the Morrison Formation, like the channel and overbank architectural styles, are indicative of at least periodic dryness.

Two sequence-bounding paleosols (or paleosol complexes) have been identified in the Morrison Formation and represent significant diastems in the part of the formation where they occur. The first is immediately above the Salt Wash Member (within the lower part of the Brushy Basin Member). This paleosol complex marks a change in fluvial style from low- to high-sinuosity platform patterns. Some contemporaneous erosion is associated with this horizon in the Dinosaur National Monument area. The climatic implication of this paleosol is no different from those of the other calcic paleosols in the Salt Wash and Brushy Basin Members and is only differentiated by its greater development and regional extent. The second sequence-bounding paleosol complex is at the top of the Brushy Basin Member, at its boundary with overlying Lower Cretaceous deposits. This paleosol represents a long period of exposure and pedogenesis ( $>5 \mathrm{my}$ ) and possibly the overprinting of different climatic regimes (wetter upon drier).

This interval is also typically overprinted by later calcretization associated with early diagenesis during deposition of overlying Lower Cretaceous deposits. These two paleosols are interpreted to mark the tops of two aggradational sequences that comprise Morrison deposition.

The calcretes of the Upper Morrison Formation-Lower Burro Canyon Formation are being studied petrographically and can be classified as mostly alpha type calcretes. That is, they consist largely of a dense micrite to microcrystalline groundmass that contains peloids, nodules, circumgranular cracks, floating grains (both detrital and authigenic), coated grains, coated fractures, and complex arrays of micro- to macro-fractures. In addition to the microcrystalline textures, some coarse recrystallized textures were observed in samples collected in Salt Valley anticline near Arches National Park, Utah. Very few biogenic textures were observed. Additional studies are 
underway that will characterize the calcretes further and, hopefully, will provide more information pertaining to the paleoclimatic conditions that governed their formation.

\section{PALEONTOLOGY}

The terrestrial facies of the Morrison is fossiliferous in all areas where the formation is sufficiently exposed to allow a reasonable chance of encountering the fossils. However, there is a variation in the geographic and stratigraphic distribution of some types of fossils. Both of these observations have important implications for resource management in the parks and monuments that contain outcrops of the Morrison Formation. In addition, Morrison faunas are diverse, including fossils of vertebrates, invertebrates, and traces of both, and plant fossils of various types. In some of the study areas, invertebrate trace fossils, including the burrows of crayfish, termites, ants, beetles, and other insects, were found to be abundant, particularly within the upper Salt Wash and lower Brushy Basin Members. This horizon may be explained by modeling Morrison sedimentation in that area as accumulation in a tectonically-controlled depositional basin with climatic and ecological controls.

Based on comparative studies of the mammalian faunas of the Morrison, there is some geographic variation. Mammal faunas from the Fruita Paleontological Area near Colorado National Monument and from Dinosaur National Monument lack docodonts, which is typical for Morrison faunas west of the Rocky Mountains. This lack of docodonts contrasts with the presence of them from even small samples of Morrison mammalian fossils east of the Rockies. This may be explained by the presence of a divide separating the Morrison into eastern and western geographic subareas, an interpretation that may be suggested by other stratigraphic evidence.

Illegal collecting of fossils within the Park Service units studied does not appear to have been intensive, in contrast to the evidence of extensive collecting on State and Federal lands adjacent to the Park Service lands. This makes the interpretation of observations on fossil occurrences somewhat problematic. In particular, the apparent scarcity of silicified wood in the vicinity of Arches National Park and Colorado National Monument relative to occurrences at Dinosaur National Monument may be the result of intensive collecting by rock hounds.

Preliminary work indicates that the dominant group of theropod dinosaurs from the Morrison Formation belong to the Family Allosauridae. A new and relatively primitive allosaurid from the Salt Wash Member that was recently excavated at Dinosaur National Monument is currently being studied. Reexamination of the original material of Saurophaginax (originally Saurophagus) from the uppermost Morrison of western Oklahoma has established that it is genetically separate from Allosaurus. Thus, at least three genera from Family Allosauridae (the new Salt Wash primitive allosaurid, Allosaurus, and Saurophaginax) existed during the Late Jurassic in the Western Interior of the United States.

Taphonomic analysis on the bivalve assemblage preserved in the Quarry Sandstone Bed at Dinosaur National Monument demonstrates that the shells occur in current-stable orientations, locally with imbricated stacking, in troughs of midchannel bars within the ancient stream bed. The shells are well sorted by size; however, fragmentation and abrasion are minimal. These features indicate a transported assemblage that has not been moved very far from the original life habitat (probably less velocity, small fluvial system). The abundance of the specimens suggests that a nearby upstream optimum habitat for unionid bivalves provided shells from the dead and decayed members of the population. Only a few articulated specimens have been found and they are generally not in life position, suggesting they were transported, buried, and unable to reestablish life functions. The disarticulated valves, which dominate the bivalve assemblages, require days to weeks of postmortem decay of the ligament to disjoin the valves, suggesting that the fauna represents a transported death assemblage. The unique dispersal mechanism employed by unionacean bivalves permits documentation of paleodrainage confluence patterns, which will enhance understanding the paleogeography of the Morrison basin.

Paleoecological interpretations comparing the ostreacode and charophyte genera with their modern counterparts suggest mostly nonmarine environments, although the salinity could have been slightly higher in several beds, perhaps to about 16 parts per thousand in some cases. An analysis of the 
spatial distribution of both ostracodes and charophytes suggests close but complex biogeographic relationships between North America and Europe during the Late Jurassic.

The wide variety of palynomorphs suggests that much of the Morrison depositional basin contained a highly diverse mesic flora during much or most of Morrison time.

Molds of the unique fossil plant, Hermanophyton, were found in sandstone beds of the Brushy Basin Member at East McElmo Creek north of the Four Corners area in Colorado. The habitat of Hermanophyton is present, uncertain. However the "grub-holes" caused by insects of the Cupedidae in Hermanophyton fossils suggest that these plants grew in a reasonably moist, forested environment. The concept of these plants existing under forested conditions is reinforced by the numerous other permineralized conifer logs preserved with specimens of this genus at the East McElmo Creek locality. Its growth increments, as well as those of associated conifers, varied from a few narrow to mostly broad ones, which also suggest that the Hermanophyton plants grew in a moist environment with occasional periods of dryness. However, the increments in Hermanophyton may or may not represent seasonal changes. Ample moisture from precipitation and (or) a shallow water table must have been present for the Hermanophyton plants to have attained their more than $16 \mathrm{~m}(53 \mathrm{ft})$ height. Thus, the macrofossil plant remains tend to support the mesic climatic interpretation that is based on the palynomorphs.

The integration of ichnological (i.e., trace fossil) information combined with paleontological, sedimentological, paleopedological, and geochemical data, produces a more holistic reconstruction of the paleoecological settings during Morrison times. Though some contradictions do exist between different sources of data, the results are still meaningful. In general, the traces reflect the sedimentological pattern of a drier climatic setting in the lower Morrison to a slightly more seasonally wet climatic setting at the end of Morrison deposition. The interpretations deduced from the trace fossils corroborates many of the interpretations from the molluscs, pollen, and plants that suggest there were periods of seasonally ample rainfall during deposition of portions of the Morrison Formation. The trace fossils, along with the carbonate paleosols and geochemical analysis, support a seasonally wet-dry climatic setting for most of the Morrison, but differs in that the traces (especially the rhizoliths and crayfish) show slightly higher precipitation than what might be expected. The diversity of invertebrate and vertebrate body fossils and trace fossils (e.g. invertebrates) suggests that the overall sedimentologic and paleoenvironmental landscapes had to sustain climates analogous or roughly analogous to today's savannah of the southern African continent. The larger vertebrates probably migrated latitudinally between conterminous landscapes shaped by different depositional systems.

\section{STABLE ISOTOPE GEOCHEMISTRY}

Many fossil materials retain their carbon and oxygen stable isotopic compositions through geologic time. A suite of materials from the Morrison Formation (fossil soil nodules, plant materials, eggshells, teeth, lake sediments) have been analyzed to determine patterns in the distribution of isotopes. Focus during the last year was on carbonate nodules from paleosols (fossil soils) in the Brushy Basin Member of the Morrison Formation. The isotopic data are evidence of a rain shadow operating in much of the Western Interior during the Late Jurassic; which is consistent with paleogeographic reconstructions that place the Morrison landscape east of a Mesocordilleran mountain range.

\section{AGE DETERMINATIONS}

Research on the relative age of the Morrison Formation based on studies of palynomorphs (spores, pollen, and dinoflagellates) and calcareous microfossils (charophytes and ostracodes) has established a much more refined relative age for the formation. It is now clear that all of the Morrison Formation and related beds are entirely Late Jurassic in age and were deposited during the latest Oxfordian, Kimmeridgian, and early Tithonian Ages. None of the microfossil evidence corroborates previously published accounts proposing an Early Cretaceous age for some of these beds.

Isotopic dating of altered volcanic ash beds in the Morrison Formation in Utah and Colorado yielded numerical ages in terms of millions of years before the present (Ma). The Brushy Basin Member at the top of the formation gives single-crystal, 
laser-fusion and step-heating, plateau ${ }^{40} \mathrm{Ar} /{ }^{39} \mathrm{Ar}$ ages on sanidine that range between $147.8 \mathrm{Ma}$ at the top of the member and $150.2 \mathrm{Ma}$ at the base of the member. The Tidwell Member at the base of the formation contains one datable ash bed about $3 \mathrm{~m}$ $(10 \mathrm{ft}$ ) above the $\mathrm{J}-5$ unconformity that has been found in at least two widely separated localities. This bed has been dated using ${ }^{40} \mathrm{Ar} /{ }^{39} \mathrm{Ar}$ dating of sanidine and gives ages ranging between 154.75 and 154.87 Ma. The Morrison Formation, therefore, ranges in age from about 147 to $155 \mathrm{Ma}$. By comparison with recent standard geologic time scales that attempt to calibrate the relative time scale based upon fossils with isotopic dates, the Morrison Formation and related beds are entirely Late Jurassic in age.

\section{$\downarrow \quad$ FUTURE WORK}

Framework studies will continue in the northern part of the study area (chiefly Wyoming and Montana), to resolve the stratigraphic problems with the upper contact of the Morrison Formation. Our work to date indicates that a major revision of the upper contact may be required, and further stratigraphic work, with additional sampling for datable material is required. Additional work is also required to resolve the stratigraphic relationships with the underlying nearshore marine Swift Formation as well. We will also lead a field trip to the northern part of the Morrison depositional basin so that the various specialists on the project can gain an understanding of the stratigraphic framework for positioning and proper interpretation of their data. We will also take other project scientists to specific areas as needed. For example, a trip to the southern part of the San Juan Basin is planned for examining and interpreting coarse material in the lower Morrison, paleosols within the Recapture Member, and fluvial styles in the upper part of the Brushy Basin Member.

\section{$\uparrow \quad$ LITERATURE CITED}

Turner, C., and Peterson, F., 1996, Morrison Ecosystem Project; In: Harlow, H.J., and Harlow, M., (eds.), 18th Annual Report 1994: University of Wyoming-National Park Service Research Center, p. 152-155. 